\title{
Introspection of Alternative Aviation Fuel Processing Technology: Benchmarks and Challenges
}

\author{
Qummare Azam, Ahmed Mahjub Alhaj, Siti Zubaidah Sulaiman, Nurul Musfirah Mazlan
}

\begin{abstract}
Aviation industry is one of the main contributors and fastest-growing sectors in the world economy. Fuel consumption from this industry is one of the major issues that have drawn the attention of both professionals and researchers in recent years. The high dependency along with the high consumption of aviation fuel on petroleum plays a crucial role in environmental degradation due to increased carbon dioxide and other emissions, as well as in the increasing rate of fossil fuel depletion. Therefore, various potential technologies have been developed and further investigated to produce alternative aviation fuels, especially biofuels. In this article, principles, sustainability, and main concerns of different alternative aviation fuel processing technologies, with some focus on biofuels, are discussed in challenges and possible remedies. The major ecological problems connected with the application of conventional jet fuels in contrast to The advantages of biofuels implementation in the aviation industry are also highlighted. This work is aimed to show the state of the art of current alternative aviation fuels, their production technologies, and the potentiality of replacing the conventional jet fuel.
\end{abstract}

Keywords: Alternative fuel, challenges, greenhouse emission, limitations, processing technology.

The environmental condition is on our headlines due to the pollution and depletion of petroleum. The drowning of the world economy and the concern on inflation on fuel prices, it is vitally important to move towards renewably clean, efficient, and sustainable alternative fuel or the production of alternative fuel [1]. The aviation industry is developing due to the rise up the number of passengers flying across the world, so the demand for production and supply process should not get affected. Research started on every segment related to aviation, and fuel is one of them to power the industry. The fuel production technologies related assignments monitoring on a prior basis to achieve all criteria to the previous energy-efficient products.

\section{Revised Manuscript Received on February 05, 2020.}

* Correspondence Author

Qummare Azam, School of Aerospace Engineering, Engineering Campus, Universiti Sains Malaysia, Nibong Tebal, Pulau Pinang, 14300, Malaysia.Email: qazam01@gmail.com

Nurul Musfirah Mazlan*, School of Aerospace Engineering, Engineering Campus, Universiti Sains Malaysia, Nibong Tebal, Pulau Pinang, 14300, Malaysia. Email: nmusfirah@usm.my.

Siti Zubaidah Sulaiman, Faculty of Chemical and Natural Resources Engineering, Universiti Malaysia Pahang, 26300 Kuantan, Pahang, Malaysia.Email: szubaidah@ump.edu.my

Ahmed Mahjub Alhaj, School of Aerospace Engineering, Engineering Campus, Universiti Sains Malaysia, Nibong Tebal, Pulau Pinang, 14300, Malaysia. Email: ahmed.ac26@gmail.com

(C) The Authors. Published by Blue Eyes Intelligence Engineering and Sciences Publication (BEIESP). This is an open access article under the CC BY-NC-ND license (http://creativecommons.org/licenses/by-nc-nd/4.0/)

\section{INTRODUCTION}

Aviation industries are currently running on liquid fuel that has a thin gap of tolerance on energy content. Liquid fuels are easy to handle than other forms of fuel, such as gases and solid form, so the possibilities have widened space to develop and distribute. The consumption of jet fuels has been increased from 191.1 million gallons per day in 2000 to 198.3 million gallons per day in 2008. As per the statistics, $10-15 \%$ of aircraft operating cost is bearded by the fuel only [2]. The hike in the price of the fuel directly hit on availability and thoroughly shifted to alternative sources or production technology. In 2007, the European parliament concerned about the European GHGs-emission trading system. They voted and issued legislation that confers if airlines fly into European regulatory regions have to decrease GHGs emissions by $10 \%$ or have to buy $\mathrm{CO}_{2}$ permitted amount [3]. Aviation industries lost billions of dollars to get $\mathrm{CO}_{2}$ allowance, and then the industries started the improvement policies in terms of engine, airframe technology, and other aspects of aircraft principle measures. However, aviation fuel also needed a replacement with alternative fuel.

The most common fossil fuel derived jet fuel used by the United States based on ASTM D1655 standards, and the United Kingdom relied on DEFSTAN. Russia used GHOST and DCSEA found by France on another similar specification. Aviation kerosene also comes in a row as a successful aviation fuel with safe, reliable and secure availability. End of December 2007, DEFSTAN achieved a unique fuel as synthetic fuel that certified for all commercial and defense aviation engines [4]. The new era started with the latest specification of ASTM D7566 for blends with synthetic fuels. However, Aviation fuels synthesized from different sources and different methods. The production of alternative fuels changes their characteristics features with the production technology. The process of production decides the properties of the fuel and that is discussed in later sections of this paper.

Among environmental impact factors of aviation, emissions to air, especially at high altitudes, emissions from ground operations (airport operations, fuel production, etc.) and noise, as well as the sustainability of the overall sector, are of significant importance. Besides $\mathrm{CO}_{2}$, it is the emission of $\mathrm{NO}_{\mathrm{x}}$, water vapor, and particulates at the altitude that account for the other impacts of aviation emissions. This paper outlines the possibilities for alternative jet fuels in the near and mid-term future, giving a background for jet fuel processing technology. The benchmarks are presented, and the challenges are discussed. 


\section{Introspection of Alternative Aviation Fuel Processing Technology: Benchmarks and Challenges}

Possible future fuels are introduced shortly and their potential for future use as aviation biofuels is discussed.

\section{A. Basic Principles and Benchmark for sustainable Biofuel Production}

The following points stand for the set the goal for biofuel production in order to check the various effects on quality and climate change [5].

- Legal Issues: The produced biofuel operations should be based on applicable rules and regulations.

- Planning, Monitoring, and Continuous improvement: The biofuel operation should be adequately planned to implement to monitor the performance for further enhancement to use to manage on an economic basis.

- Greenhouse Gas Emissions: Biofuels operation contributes to atmospheric alteration by noticeably reducing lifecycle GHG emissions as compared to fossil fuels.

- Human and Labor Rights: Biofuel operations should not be violating human rights or hazardous during production and supply.

- Rural ad Social Development: the social welfare in regions of poverty, biofuel operations should contribute to the social and economic development of local, agricultural, and indigenous people and communities.

- Local food security: Biofuel operations should ensure the human right to provide an adequate amount of food and improve food security.

- Conservation: Biofuel operations should be avoiding the adverse effects on biodiversity and conservation values.

- Soil, Air, and water: Biofuel production body shall implement a program that reverses soil degradation and/or maintains soil health for bio crops cultivation. Air pollution should be minimum and conserve water rights.

- Use of technology, Inputs, and Management of waste: The purpose of technologies in biofuel operations shall seek to maximize production efficiency and social and environmental performance and minimize the risk of damages to the environment and people.

- Land rights: Biofuel operations shall respect land rights and land use rights.

\section{ALTERNATIVE FUELS PRODUCTION TECHNOLOGIES}

Fuel processing from different sources is inherently noticeable regarding fuel selection. The processes define the characteristic features of fuel according to feedstock supply. There are various designed technologies of production that affect fuel expenses, affordability, categorized properties, and appropriate uses describes below in Table 1. Mostly for the production of hydrocarbon fuels follows two processes shown in Fig. 1.

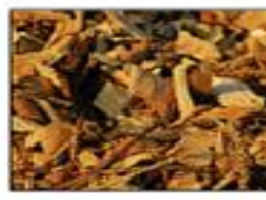

Biomass

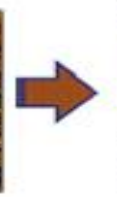

Processing Technology

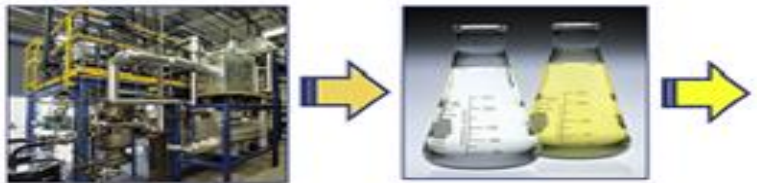

Fuel Outcomes

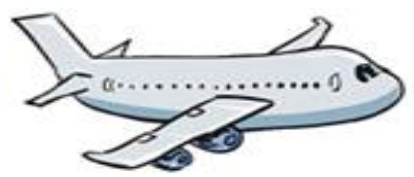

In use aircraft

Fig. 1.Conversion Process of Fuel [1].

\section{A. Thermochemical technology}

Thermochemical technology defines the heat treatment process and the chemical combination to extract the fuel in the usable form [6]. The means by the heat degrades the biomass in the absence of air. The product formed as biofuel and other usable outcomes. The different process with the gaseous catalysts for the pyrolysis outcomes to create syngas. The outcome gases from pyrolysis are the mixture of hydrogen and carbon monoxide [7]. A further process with the help of FT technology formed biofuel, followed by hydroprocessing technology. The fuel processing has different pathways to the final product. Biomass to liquid technology describes the biomass to hydrocarbon. The processes always rely on feedstock to continue. The waste of different ranges like cellulose, plant-related waste, and algae as a source for conversion to biofuel or hydrocarbon. The method to convert syngas and followed by FT pyrolysis resulted as hydroprocessing [8]. This process outcomes fuel has the capability to sustain and minimum greenhouse emission gasses.

The FT method defines the catalytic transform of carbon dioxide and hydrogen gas as a result of the gasification of biomass to a liquid state of hydrocarbon [9]. The nature of hydrocarbon turn to a catalyst and some other factor such as temperature, pressure and other conditions [10]. The aviation fuels produce to followed by the FT process, have the same feature from different sources [11]. The outcomes from the FT method have low Sulphur oil and the absence of aroma. The blending with the FT processed fuels with some conventional fuels and found clean-burning and negligible Sulphur content [12]. The blending mostly focused on viscosity and energy efficiency. FT process resulted in a low emission of carbon monoxide and carbon dioxide gasses. Furthermore, additives can make out of leakage from the engine. FT process has a considerable range of feedstocks but costly.

\section{B. Hydroprocessing}

The hydroprocessing associated with vegetable oils, organic fats, and other animal fats, furthermore can be treated with hydrogen and catalysts to remove oxygen from the source is called isomerization, which is an in-between process [13]. 
The conversion of fat to hydrocarbon featured as lowtemperature fuel. Hydroprocessed renewable jet fuels (HRJF) content, no Sulphur, no burning residue, and appropriate thermal compatibility [14]. In this process of deoxygenation, oxygen separate in the form of water and the other side product [13]. There are different types of sources used as feedstock like camelina, algae, other vegetable fats, and animal fats. The process is very appropriate and produces better results in the context of a high cetane number. The hydroprocessing technology is one of the best technology to produce jet fuel [15]. Nowadays, this processing technology used for military jet fuel and commercially available. HRJF characteristic features are more likely to other conventional fuel but comparatively, it has a higher cetane number. Renewable fats have various saturation scale points to break and different processes to saturate with a wide range of catalysts [16]. Catalytic hydrogenation can process to unsaturated liquid form to saturate double bonds with the help of hydrogen [17]. The further process is to break the propane to develop fatty acids. Hydrogen or thermal hydrolysis converts the glycerol part to propane [18]. The hydrogen molecule makes a compound with glycerol molecule that forms a compound of glycerol and fatty acids compounds. After the process, additives can also use and blending is possible as well to modify lubricity [19]. To achieve the level of standard fuel specifications, jet fuel has a high flash point and cold flow properties and the HRJF process can provide the treatment to reach.

\section{Biochemical process}

The biological treatment of sugar by using biomedical chemicals to develop hydrocarbons to generate aviation fuels and byproducts. The layout of sugar from biomass followed by biochemical to liquid form to hydrocarbon. The fermentation process of sugar can directly convert into hydrocarbon by using some additives [20]. The key features of this process have effective production cost, sustainability, availability, and lesser greenhouse emission. Carbohydrates convert into alcohol by using the biochemical process via fermentation with the help of thermochemical procedures to formed syngas to hydrocarbons [21]. A massive scale of feedstock can be developed by starch, sugar, and cellulose. It goes through four procedures, dehydration, oligomerization, distillation, and hydrogenation, and commonly commercialized due to the low-cost process. Biofuels directly converted from alcohol by the fermentation process and followed by the gasification process [22].

Biomass processed by hydrolysis to derive the form of carbohydrates, further processes by using biochemical to produce bio alcohol [23]. Biomass is the principal source of renewable potential energy feedstocks. Direct fermentation of sugar attempt to alcohol. The other forms of alcohol have specific uses and different procedures to develop.

\section{ALTERNATIVE FUELS LIMITATIONS}

\section{A. Environmental challenges}

The environmental challenges due to greenhouse emissions focused during fuel selection and the process of production. The level of emitted gases is always increasing due to frequent uses of air transport. Air transport emission participates in approximately 3\% of total greenhouse gases in 2008, but as per assumption from the previous data, it will be touch the double value around 6\% till 2050 [24]. The curiosity of demanding research affected the biomass and reduced forest. Deforestation comes with other consequences like increasing the carbon dioxide, soil erosion, and alteration of the biological cycle. For the production of biomass, the use of regular cropland reduces food crop cultivation, which creates a shortage of food. Proper planting of biofuel crops minimizes the strength of the soil, and further applications of crop chemicals like pesticides pollute the air and water [25].

\section{B. Production issues}

The production follows the cost-effective measures as per feedstock requirements. Some of the development processes of jet fuels found very costly and complicated, like the synthesis of algae [26]. The extraction and the procedure used in algae conversion to fuel is very tricky to choose the pathways, including cost and effective outcomes [27]. The selection of fuel conversion catalyst is even a complicated issue. Every production flow chart needs to change in features that create a gap to be commercialized. The processing of sources has a variant process as per feedstock requirement, so the stability breaks the efficiency and compatibility. Blended Alcohol-related production process settled with fermentation, but the uses made the engine modification [28].

\section{Distribution problems}

The supply and storage system associated with care and safety. Alteration in fuel quality during the process of distribution, especially for the blended fuels found as complicated [29]. The input cost for the distribution of hydroprocessed fuels is more than that of regular jet fuels [30]. The whole procedure from extraction to conversion into fuel to the commercialization of fuel is mostly carried out by different steps of storage and distribution. Some of the fuels are volatile, so the specific design can only hold its stability. The main issues are still revolving around the overall expenses to stabilize and feasible for distributors and suppliers.

\section{Feedstock availability and sustainability}

The most remarkable fact of recent researches, unlimited availability of source material for a continuous supply. A vast range of feedstock source availability directly affects low-cost outcomes. Feedstock testing needs fuel availability in a considerable amount to face the challenge of future alternative fuel. Algae have severe issues of temperature stability according to its organic nature to sustain [26]. The crop selection for renewable jet fuel mentions the least use of cropland and other inputs. The feedstock requirement with a minimum range of water as resulted in the right amount of yield, no effect on food crops and negligible content of emission particles to become feedstock availability and sustainability. 


\section{E. Compatibility with conventional fuel}

Renewable fuels depend on efficiency and other characteristic features in comparison to conventional jet fuel. The capability checks the measures of availability and greenhouse emission of alternative fuels in terms of conventional fuel's flashpoint value, Sulphur content, and the other additive should match or enhanced form in all aspects [38]. Most of the alternative fuels failed to use in jet engines due to various issues [39]. Some of the alternative fuels have high scale values but not easy to sustain with the machine [20]. Additionally, the Thermal effect is one of the significant keywords of biofuels quality but the compatibility recommendation should follow the overall aspects for the right fuel [40]. The performance should be enhanced but safety must be on high consideration.

Table- I: Fuel products and Processing technology.

\begin{tabular}{|c|c|c|c|c|c|}
\hline $\begin{array}{c}\text { Alternative Fuel } \\
\text { Sources } \\
\end{array}$ & Processes & Pre-product & Techniques & Fuel Product & Ref \\
\hline \multirow[t]{2}{*}{ Used cooking oil } & \multirow[t]{2}{*}{ Cleaning and upgrading } & \multirow[t]{2}{*}{ Fatty acid } & Esterification & Biodiesel & \multirow[t]{2}{*}[31]{} \\
\hline & & & Hydrotreatment & $\begin{array}{c}\text { Vegetables oil-based } \\
\text { bio-fuel }\end{array}$ & \\
\hline \multirow[t]{2}{*}{ Tallow } & \multirow[t]{2}{*}{ Cleaning and upgrading } & Fatty acid & Esterification & \multirow[t]{2}{*}{ Biodiesel } & \multirow[t]{2}{*}[32]{} \\
\hline & & lipid & Hydrocracking & & \\
\hline Crude tall oil & Cleaning and upgrading & Lipid & Esterification & Biodiesel & $\begin{array}{l}{[32,} \\
33]\end{array}$ \\
\hline Oilseed, Flaxseed & Crushing and Extraction & Lipid & Hydrocatalytic/Hydrotermolysis & $\begin{array}{c}\text { Vegetables oil-based } \\
\text { bio-fuel }\end{array}$ & [32] \\
\hline \multirow[t]{2}{*}{ Algae } & \multirow[t]{2}{*}{ Crushing and Extraction } & \multirow[t]{2}{*}{ Lipid } & Esterification & Biodiesel & {$[1]$} \\
\hline & & & Hydrocatalytic/Hydrotermolysis & $\begin{array}{c}\text { Vegetables oil-based } \\
\text { bio-fuel }\end{array}$ & \\
\hline Sugar/starch & Catalytic/Fermentation of sugar & Alkane, hydrocarbon, Alcohol & $\begin{array}{l}\text { Catalytic conversion and hydro- } \\
\text { treatment }\end{array}$ & Bio-fuel & [5] \\
\hline \multirow[t]{4}{*}{$\begin{array}{l}\text { Lignocellulosic biomass } \\
\text { and waste, Camelina }\end{array}$} & \multirow[t]{2}{*}{$\begin{array}{l}\text { Biomass fraction Hydrolysis, } \\
\text { fermentation, Oil Extraction }\end{array}$} & Alcohol & $\begin{array}{l}\text { Dehydration, oligomerization, } \\
\text { hydroprocessing }\end{array}$ & Biofuel & \multirow[t]{3}{*}{$\begin{array}{l}{[32,} \\
34, \\
35]\end{array}$} \\
\hline & & lignin & Catalytic, hydrotreatment & $\begin{array}{c}\text { Phenolics, BTX, } \\
\text { Biofuel, intermediate }\end{array}$ & \\
\hline & \multirow[t]{2}{*}{ Drying, comminution } & Pyrolysis & $\begin{array}{l}\text { Hydrogenation, Deoxygenetion, and } \\
\text { fractionation }\end{array}$ & $\begin{array}{c}\text { Green diesel, paraffin, } \\
\text { naphthenic } \\
\text { compounds } \\
\end{array}$ & \\
\hline & & gasification & Fischer Tropsch and frantionation & BTL Fuels & $\begin{array}{l}{[5,} \\
36]\end{array}$ \\
\hline $\begin{array}{c}\text { Soybean, jatropha, palm } \\
\text { rapeseed }\end{array}$ & Oil extraction & Hydrotratment/catalytic & Hydroprocessing & HEFA jet fuel & $\begin{array}{l}{[32,} \\
37]\end{array}$ \\
\hline
\end{tabular}

\section{CONCLUSION}

In this effort, various alternative aviation fuel processing technologies have been reviewed based on different renewable sources and feedstocks. The main challenges that have risen so far are those related to the environmental impact, production issues, distribution difficulty, availability, and compatibility of feedstocks. According to the literature, Hydro-processing of fuel and Fischer Tropsch process have been found the most commercially viable. However, published results showed that aviation fuels produced from renewable sources are expected to replace fossil-based fuels in the future, as the production technologies are getting advanced and the alternative fuel is becoming more affordable and accessible day by day.

The co-operation of the aviation industry sector, public sector, agricultural institutions, research organizations is required for establishing more efficient infrastructure and procedures for the smooth incorporation of alternative aviation fuels. This effort may serve as an initial guide for future dedicated studies on addressing each highlighted challenge in more dedication.

\section{ACKNOWLEDGMENT}

The authors would like to thank Universiti Sains Malaysia Research University Grant (Grant No: 1001/PAERO/8014019) and USM fellowship scheme for funding this work.

\section{REFERENCES}

1. N. Yilmaz and A. Atmanli, "Sustainable alternative fuels in aviation," Energy, vol. 140, pp. 1378-1386, 2017.

2. G. Liu, B. Yan, and G. Chen, "Technical review on jet fuel production," Renewable and Sustainable Energy Reviews, vol. 25, pp. 59-70, 2013.

3. J. Scheelhaase, W. Grimme, and M. Schaefer, "The inclusion of aviation into the EU emission trading scheme-Impacts on competition between European and non-European network airlines," Transportation Research Part D: Transport and Environment, vol. 15, pp. 14-25, 2010.

4. C. A. Moses and P. N. Roets, "Properties, characteristics, and combustion performance of sasol fully synthetic jet fuel," Journal of Engineering for Gas turbines and Power, vol. 131, 2009.

5. A. Faaij and M. van Dijk, "White paper on sustainable jet fuel," SkyNRG, Utrecht, The Netherlands, accessed Mar, vol. 26, p. 2019 2012. 
6. H. Weldekidan, V. Strezov, and G. Town, "Review of solar energy for biofuel extraction," Renewable and Sustainable Energy Reviews, vol. 88, pp. 184-192, 2018.

7. P. Basu, Biomass gasification, pyrolysis and torrefaction: practical design and theory: Academic press, 2018.

8. S. Kresnyak, S. Price, and J. Wagner, "Enhancement of FischerTropsch Process for Hydrocarbon Fuel Formulation in a GTL Environment," ed: Google Patents, 2018.

9. M. Hillestad, M. Ostadi, G. A. Serrano, E. Rytter, B. Austbø, J. Pharoah, et al., "Improving carbon efficiency and profitability of the biomass to liquid process with hydrogen from renewable power," Fuel, vol. 234, pp. 1431-1451, 2018.

10. M. Kumar, A. O. Oyedun, and A. Kumar, "A review on the current status of various hydrothermal technologies on biomass feedstock," Renewable and Sustainable Energy Reviews, vol. 81, pp. 1742-1770, 2018.

11. A. Starik, A. Savel'ev, O. Favorskii, and N. Titova, "Analysis of emission characteristics of gas turbine engines with some alternative fuels," International journal of green energy, vol. 15, pp. 161-168, 2018.

12. R. H. Moore, K. L. Thornhill, B. Weinzierl, D. Sauer, E. D'Ascoli, J. Kim, et al., "Biofuel blending reduces particle emissions from aircraft engines at cruise conditions," Nature, vol. 543, p. 411, 2017.

13. U. Neuling and M. Kaltschmitt, "Liquid Fuels from Vegetable Oil," Energy from Organic Materials (Biomass) A Volume in the Encyclopedia of Sustainability Science and Technology, Second Edition, pp. 881-904, 2019.

14. A. Elgowainy, J. Han, M. Wang, N. Carter, R. Stratton, J. Hileman, et al., "Life-cycle analysis of alternative aviation fuels in GREET," Argonne National Lab.(ANL), Argonne, IL (United States)2012.

15. J. Yang, Z. Xin, K. Corscadden, and H. Niu, "An overview on performance characteristics of bio-jet fuels," Fuel, vol. 237, pp. 916936, 2019.

16. L. C. Meher, D. V. Sagar, and S. Naik, "Technical aspects of biodiesel production by transesterification-a review," Renewable and sustainable energy reviews, vol. 10, pp. 248-268, 2006.

17. S.-R. Juan Carlos, "Catalytic routes for the conversion of biomass into liquid hydrocarbon transportation fuels," Energy\&Environmental Science, vol. 4, 2010.

18. C.-W. Chiu, A. Tekeei, J. M. Ronco, M.-L. Banks, and G. J. Suppes, "Reducing byproduct formation during conversion of glycerol to propylene glycol," Industrial \& Engineering Chemistry Research, vol. 47, pp. 6878-6884, 2008

19. A. Llamas, A.-M. Al-Lal, M. Hernandez, M. Lapuerta, and L. Canoira, "Biokerosene from babassu and camelina oils: Production and properties of their blends with fossil kerosene," Energy \& fuels, vol. 26, pp. 5968-5976, 2012.

20. J. Pechstein, U. Neuling, J. Gebauer, and M. Kaltschmitt, "Alcoholto-Jet (AtJ)," in Biokerosene, ed: Springer, 2018, pp. 543-574.

21. K. Ullah, V. K. Sharma, M. Ahmad, P. Lv, J. Krahl, and Z. Wang, "The insight views of advanced technologies and its application in bio-origin fuel synthesis from lignocellulose biomasses waste, a review," Renewable and sustainable energy reviews, vol. 82, pp. 3992-4008, 2018.

22. L. P. Koh and J. Ghazoul, "Biofuels, biodiversity, and people: understanding the conflicts and finding opportunities," Biological conservation, vol. 141, pp. 2450-2460, 2008.

23. K. Ghasemzadeh, E. Jalilnejad, and A. Basile, "Production of bioalcohol and biomethane," in Bioenergy Systems for the Future, ed: Elsevier, 2017, pp. 61-86.

24. D. S. Lee, G. Pitari, V. Grewe, K. Gierens, J. Penner, A. Petzold, et al., "Transport impacts on atmosphere and climate: Aviation," Atmospheric environment, vol. 44, pp. 4678-4734, 2010.

25. R. Dominguez-Faus, S. E. Powers, J. G. Burken, and P. J. Alvarez, "The water footprint of biofuels: A drink or drive issue?," ed: ACS Publications, 2009.

26. O. M. Adeniyi, U. Azimov, and A. Burluka, "Algae biofuel: Current status and future applications," Renewable and sustainable energy reviews, vol. 90, pp. 316-335, 2018.

27. E. S. Shuba and D. Kifle, "Microalgae to biofuels: 'Promising'alternative and renewable energy, review," Renewable and Sustainable Energy Reviews, vol. 81, pp. 743-755, 2018.

28. Y. Dahman, K. Syed, S. Begum, P. Roy, and B. Mohtasebi, "Biofuels: Their characteristics and analysis," in Biomass, Biopolymer-Based Materials, and Bioenergy, ed: Elsevier, 2019, pp. 277-325.

29. R. H. Moore, M. Shook, A. Beyersdorf, C. Corr, S. Herndon, W. B. Knighton, et al., "Influence of jet fuel composition on aircraft engine emissions: A synthesis of aerosol emissions data from the NASA
APEX, AAFEX, and ACCESS missions," Energy \& Fuels, vol. 29, pp. 2591-2600, 2015.

30. Y. Gang, X. Zhang, X. Lei, H. Guo, W. Li, and D. Li, "Hydroprocessing of low-temperature coal tar to produce jet fuel," RSC advances, vol. 8, pp. 23663-23670, 2018.

31. Z. Shah, R. C. Veses, J. C. Vaghetti, V. D. Amorim, and R. d. Silva, "Preparation of jet engine range fuel from biomass pyrolysis oil through hydrogenation and its comparison with aviation kerosene," International journal of green energy, vol. 16, pp. 350-360, 2019.

32. C. Gutiérrez-Antonio, F. Gómez-Castro, J. de Lira-Flores, and S Hernández, "A review on the production processes of renewable jet fuel," Renewable and Sustainable Energy Reviews, vol. 79, pp. 709729, 2017.

33. T. Ahmad, M. Danish, P. Kale, B. Geremew, S. B. Adeloju, M. Nizami, et al., "Optimization of process variables for biodiesel production by transesterification of flaxseed oil and produced biodiesel characterizations," Renewable energy, vol. 139, pp. 1272 1280, 2019.

34. M. Berchtold, J. Fimberger, A. Reichhold, and P. Pucher, "Upgrading of heat carrier oil derived from liquid-phase pyrolysis via fluid catalytic cracking," Fuel Processing Technology, vol. 142, pp. 92-99, 2016.

35. A. Agarwal, M. Rana, and J.-H. Park, "Advancement in technologies for the depolymerization of lignin," Fuel processing technology, vol 181, pp. 115-132, 2018.

36. J. Hileman, H. M. Wong, D. Ortiz, N. Brown, L. Maurice, and M. Rumizen, "The feasibility and potential environmental benefits of alternative fuels for commercial aviation," in Proceedings of the 26th International Congress of the Aeronautical Sciences, 2008, pp. 5-8.

37. D. Kochetkova, J. Blažek, P. Šimáček, M. Staš, and Z. Beňo, "Influence of rapeseed oil hydrotreating on hydrogenation activity of CoMo catalyst," Fuel Processing Technology, vol. 142, pp. 319-325, 2016.

38. P. Kallio, A. Pásztor, M. K. Akhtar, and P. R. Jones, "Renewable jet fuel," Current opinion in biotechnology, vol. 26, pp. 50-55, 2014.

39. B. Khandelwal, C. J. Wijesinghe, and S. Sriraman, "Effect of Alternative Fuels on Emissions and Engine Compatibility," in Energy for Propulsion, ed: Springer, 2018, pp. 27-50.

40. M. Grisanti, R. Parthasarathy, and S. Gollahalli, "Physical and combustion properties of biofuels and biofuel blends with petroleum fuels," in 9th Annual International Energy Conversion Engineering Conference, 2011, p. 6012

\section{AUTHORS PROFILE}

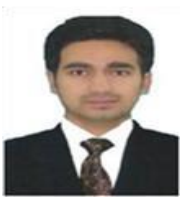

Qummare Azam, is a current Ph.D. researcher in the School of Aerospace Engineering at Universiti Sains Malaysia, Malaysia. His areas of interest include aerodynamics, CFD Simulation, and finite element modelling and presently working on Bio-fuel combustion. He has done an M.Sc. degree by research in the School of Mechanical Engineering on drag reduction by using micro-jets technology and published research papers. $\mathrm{He}$ received $\mathrm{B}$.Tech. degree in mechanical engineering from the ICFAI University, Dehradun in 2014, India.



Nurul Musfirah Mazlan, is a lecturer at the School of Aerospace Engineering, Universiti Sains Malaysia. She obtained a bachelor's degree in Aerospace Engineering from Universiti Sains Malaysia, Malaysia. She obtained M.Sc and Ph.D. degrees are from Cranfield University U.K. Her areas of research are propulsion system and performance and alternative fuel.

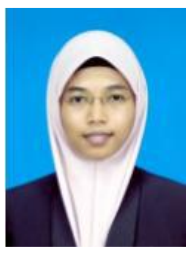

Siti Zubaidah Binti Sulaiman, is currently a senior lecturer at Universiti Malaysia Pahang (UMP). She obtained a degree and master's in chemical engineering from Universiti Putra Malaysia while a Ph.D. degree from Universiti Teknologi Malaysia. She is specialized in fire and explosion. She has been involved in various fields of research, for example, biogas explosion characteristic, biogas vented gas, gas explosion modelling, food-based and reactive dust explosion. 
Introspection of Alternative Aviation Fuel Processing Technology: Benchmarks and Challenges

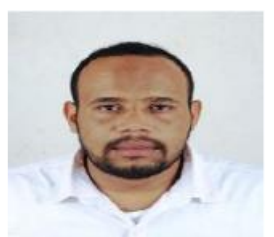

Ahmed Mahjub Alhaj, is an accredited Chemical Engineer as well as an AIAA Student Member. He received a B.Sc. and M.Sc. in chemical engineering from the University of Gezira (2009) and Karrary University (2014) respectively. In 2010, he joined Safat Aviation Group, where he involved in designing and manufacturing of aerospace propulsion systems. Currently, he is a full-time Ph.D. researcher in the field of aerospace systems design and optimization at the School of Aerospace Engineering, Universiti Sains Malaysia. 